\title{
Factors Influencing Intention to Use Intrauterine Device Among Family Planning Clients in Southwestern Ethiopia
}

\author{
Demisew Amenu \\ Jimma University \\ Tekle Wakjira \\ Jimma University \\ Alemi Kebede \\ Jimma University \\ Zerihun Asefa \\ Jimma University \\ Afework Tadele ( $\nabla$ afatadele@gmail.com ) \\ Jimma University https://orcid.org/0000-0001-5682-6117
}

\section{Research}

Keywords: Intrauterine device, Intention, family planning users, Southwest Ethiopia

Posted Date: November 9th, 2021

DOI: https://doi.org/10.21203/rs.3.rs-1040098/v1

License: (c) (i) This work is licensed under a Creative Commons Attribution 4.0 International License. Read Full License 


\section{Abstract}

Background: Intrauterine devices are the second most widely used modern family planning methods in the world. In Ethiopia, only $2 \%$ of married women use intrauterine device. Therefore, the aim of this study is to determine factors associated with the intention to use the intrauterine device in southwest, Ethiopia.

Methods: A facility-based cross-sectional design was employed to collect data from 784 women using a structured questionnaire. Data were collected from October-November,2020. Data were managed using Kobo Collect v1.25.1 and Stata version 16.0 was used for analysis. A multivariable logistic regression was employed.

Results: The prevalence of intention to use intrauterine device in this study was $30 \%$. Having an intrauterine devices information ( $A O R=2.28(1.63-3.20)$ ), being highest wealth status 1.76 $(A O R=1.76(1.07-2.95))$, and being able to read and write $(A O R=3.60 ; 95 \% \mathrm{Cl}: 1.59-7.89)$ were found to be significant factors influencing women's intention to use an intrauterine device. The most common reasons for not having an intention to use were fear of side effects, lack of knowledge, and husband disapproval.

Conclusion: An intention to use an intrauterine device was low. Public health interventions should provide an information focusing on the cited resaons reaching all the community in need, and give priority for women who unable read and write, and lowest wealth status. Further interventional studies were recommended to determine effective interventions to increase women's intention to use intrauterine device.

\section{Background}

The copper-bearing IUD is a thin, flexible plastic frame with copper sleeves or wires around it. IUD is one of the world's most widely used reversible contraceptive methods. Modern IUDs are safe, highly effective, and cost-effective forms of contraception is (1). Less than 1 pregnancy per 100 women used an IUD in the first year. This means that out of every 1,000 women using IUDs, 992 to 994 are not pregnant (2).

Contemporary or conventional, is used by two out of three reproductive-age women married or unionized in 2015 worldwide, and another $12 \%$ have an unmet need for contraception. Most basic methods, female sterilization, and IUD account for approximately 60 percent of existing methods used (3).

Latest figures from 21 developed nations, Asian countries 13\%, and Middle East and North Africa, use are the highest among all reproductive-age married women $12 \%$. The overall IUD use is the lowest in North America (1.5\%) and sub-Saharan Africa (0.8\%) (1).

The use of IUD was just \% in Kenya and 4.8 Ethiopia, as reported in the Ethiopian Demographic and Health Survey 2016 (4,5). In Ethiopia, IUD is used and ranging from 5.2\% in Addis Ababa, $0.4 \%$ in 
Gambella, to $0 \%$ in Somali (6). Study conducted in Nigeria show that the intention of intrauterine contraception devices for postpartum women was $14.7 \%$ (7).

A study done in Tigray region, North-Ethiopia and Debre Markos in North West Ethiopia found that the prevalence of intention to use IUD was $24.0 \%$ and $28.3 \%$, respectively. $(8,9)$. Interestingly, in the southwest of Ethiopia, no research has identified factors associated with intention to use the IUD.

\section{Methods}

\section{Study area and period}

A facility-based cross-sectional study design was used. A study was conducted in the Gambela, llubabor, and Bench-Sheko Zones, in Southwest Ethiopia. The study was conducted from october-November 2020 on all reproductive age group women who visited health facilities for family planning services.

\section{Source and study population}

The population for the study was of reproductive age who came to the health facilities in the selected district of the study zones and region for family planning services.

\section{Sample size and techniques}

To estimate the sample size, a single population proportion formula with the following assumptions was used. Desired precision $(d)=4 \%$, design effect 2 , Confidence level $=95 \%$, and $Z a / 2=1.96$ (value of $Z$ at $a$ 0.05 or $95 \% \mathrm{Cl}$. The proportion of long-acting and permanent contraceptive methods from the previous study done in Debre-Markos town was $19.5 \%(8)$. And by considering a $15 \%$ non-response rate, the calculated minimum sample size was 851 .

\section{Sampling techniques}

The study area was purposively selected. All hospitals from the two-zone and Gambela regions were selected, and $30 \%$ of the health centers from each zone and region were taken. Then, clients of family planning services were selected systematically after calculating $\mathrm{K}^{\text {th }}$-value based on the preceding quarter report of each health facility.

\section{Data quality control}

The data collection tool was translated into the local language and translated back to English to check its consistency. A pre-test was done on $5 \%$ of participants and some modifications were made in the final 
version of the questionnaire. During data collection, completeness and consistency of information including typing errors were checked by the supervisor and principal investigator.

\section{Data processing and analysis}

All data were electronically collected on-site and uploaded daily to the kobo server database using kobo collect v1.25.1(kobotoolbox.org). Database content was checked for missing answers, duplications, and inconsistencies. Then data were then exported to Stata software version 16.0 for further analysis. Descriptive statistics were used to determine the frequency, mean, and proportions of variables. A p-value of $\leq 0.05$ was considered statically significant. In bivariate logistics regression, a variable whose $p \leq 0.25$ was considered as a candidate for multivariable logistic regression analysis. And variables having $p \leq 0.05$ after multivariable logistic regression analysis were considered as independent predictors for knowledge. The backward elimination method was done to fit the final model. Statistical significance was assessed using the chi-square test, odds ratios, and $95 \% \mathrm{Cl}$, p values less than 0.05 used as cut off point for statistical significance.

\section{Results}

\section{Sociodemographic Characteristics}

A total of 844 women of reproductive age group, 784 participated in the study with a response rate of 93\% (Table 1). 
Table 1

Sociodemographic characteristics of the participants in Southwest Ethiopia

\begin{tabular}{|c|c|c|c|}
\hline & & Frequency (784) & Percentage \\
\hline Age & $15-19$ & 51 & 6.51 \\
\hline \multirow[t]{4}{*}{ Mean $=28 \pm 6$ years } & $20-24$ & 208 & 26.53 \\
\hline & $25-29$ & 249 & 31.76 \\
\hline & $30-34$ & 174 & 22.19 \\
\hline & $35-49$ & 102 & 13.01 \\
\hline \multirow[t]{8}{*}{ Ethnicity } & Oromo & 351 & 44.77 \\
\hline & Amhara & 112 & 14.29 \\
\hline & Agnuak & 92 & 11.73 \\
\hline & Bench & 84 & 10.71 \\
\hline & Nuer & 33 & 4.21 \\
\hline & Kaffa & 30 & 3.83 \\
\hline & Kanbata & 29 & 3.70 \\
\hline & Others & 53 & 6.76 \\
\hline \multirow[t]{4}{*}{ Marital status } & Married & 734 & 93.62 \\
\hline & Single & 25 & 3.19 \\
\hline & Separated & 16 & 2.04 \\
\hline & Widowed & 9 & 1.15 \\
\hline \multirow[t]{4}{*}{ Religion } & Protestant & 447 & 57.02 \\
\hline & Orthodox & 187 & 23.85 \\
\hline & Muslim & 146 & 18.62 \\
\hline & Others & 4 & 0.51 \\
\hline \multirow[t]{5}{*}{ Educational status } & Unable to read and write & 148 & 18.88 \\
\hline & Able to read and write & 36 & 4.59 \\
\hline & Primary School & 231 & 29.46 \\
\hline & Secondary School & 200 & 25.51 \\
\hline & Diploma & 138 & 17.60 \\
\hline
\end{tabular}




\begin{tabular}{|llll|}
\hline & & Frequency (784) & Percentage \\
\hline \multirow{2}{*}{ Respondent occupational status } & Degree and above & 31 & 3.95 \\
\cline { 2 - 4 } & Housewife & 542 & 69.13 \\
\cline { 2 - 4 } & Government employee & 141 & 17.98 \\
\cline { 2 - 4 } & Merchant & 62 & 7.91 \\
\cline { 2 - 4 } & Student & 34 & 4.34 \\
\cline { 2 - 4 } & Daily labor & 5 & 0.64 \\
\hline
\end{tabular}

\section{Obstetrics characteristics of study participants}

The mean and standard deviation of age at first sexual intercourse, first birth, and first marriage was 17.5( \pm 2.4$), 20.4( \pm 3.4)$, and $18.9( \pm 3.1)$ respectively (Table 2$)$. 
Table 2

Obstetrics characteristics of study participants in Southwest Ethiopia

\begin{tabular}{|c|c|c|c|}
\hline & & Frequency & Percentage \\
\hline \multirow[t]{2}{*}{ Ever been pregnant } & Yes & 712 & 90.8 \\
\hline & No & 72 & 9.2 \\
\hline \multirow[t]{3}{*}{ Number of pregnancies $(\mathrm{N}=712)$} & One & 230 & 32.4 \\
\hline & Two & 172 & 24.1 \\
\hline & Three and more & 310 & 43.5 \\
\hline \multirow{2}{*}{$\begin{array}{l}\text { Ever encountered unintended } \\
\text { pregnancy }\end{array}$} & Yes & 112 & 15.7 \\
\hline & No & 600 & 84.3 \\
\hline \multirow[t]{2}{*}{ Ever encountered abortion } & Yes & 68 & 9.2 \\
\hline & No & 647 & 87.3 \\
\hline \multirow[t]{2}{*}{ Ever given birth } & Yes & 643 & 90.0 \\
\hline & No & 69 & 10.0 \\
\hline \multirow[t]{2}{*}{ Ever encountered child/infant death } & Yes & 87 & 13.6 \\
\hline & No & 556 & 86.4 \\
\hline \multirow[t]{3}{*}{ Total number of children $(\mathrm{N}=698)$} & one & 237 & 36.8 \\
\hline & Two & 175 & 27.2 \\
\hline & Three and more & 231 & 35.9 \\
\hline \multirow[t]{4}{*}{ Fertility status in the last five years } & $\begin{array}{l}\text { Not pregnant in the last five } \\
\text { years }\end{array}$ & 109 & 15.3 \\
\hline & Pregnant, Not wanted at All & 15 & 2.1 \\
\hline & Pregnant, wanted later & 97 & 13.7 \\
\hline & Pregnant, wanted then & 488 & 68.9 \\
\hline
\end{tabular}

\section{Women's intention to use IUD}

In this study, the prevalence of intention to use IUD was $236(30 \%)$. The most common cited reasons for not having an intention to use IUD were fear of side effect (48.2\%), followed by lack of knowledge (17.9\%), and husband disapproval (14.2\%) (figure 1).

\section{Factors influencing family planning user's intention to use IUD}


A multivariable losgistic regresseion revealed that having ain IUD information, wealth and educational status were found to be statistically signifant factors influencing an intention to use an IUD.

Even after controlling for potential confounders having an IUD information was more than two time more likely ( $A O R=2.28(1.63-3.20)$ ) to have an intetion to use IUD compared to their counterparts.

Although IUD was being provided for free in public health facilities in the study area being in the highest wealth status about twice $1.76(A O R=1.76(1.07-2.95))$ more likely to have an intetion to use IUD compared to the lowest wealth status.

Furthermore, women who able to read and write were more than three times (AOR $=3.60 ; 95 \% \mathrm{Cl}: 1.59$ 7.89) more likely to have an intention to use IUD compared to those who unable to read \& write (Table 3 ).

Table 3

Multivariable logistic regression analysis of factors influencing family planning user's intention to use IUD in Southwest Ethiopia

\begin{tabular}{|c|c|c|c|c|c|c|}
\hline \multirow[t]{2}{*}{ Variables } & \multicolumn{3}{|l|}{ IUD intension } & \multirow[t]{2}{*}{ COR } & \multirow[t]{2}{*}{ AOR } & \multirow{2}{*}{$\begin{array}{l}\mathrm{p}- \\
\text { value }\end{array}$} \\
\hline & Category & No & Yes & & & \\
\hline \multirow[t]{2}{*}{ IUD Information } & No & 298 & 78 & 1 & 1 & . \\
\hline & Yes & 250 & 158 & $\begin{array}{l}2.41(1.75- \\
3.32)\end{array}$ & $\begin{array}{l}2.28(1.63- \\
3.20)\end{array}$ & 0.000 \\
\hline \multirow[t]{3}{*}{ Wealth index } & Poor & 205 & 57 & 1 & 1 & \\
\hline & Average & 183 & 80 & $\begin{array}{l}1.57(1.06- \\
2.33)\end{array}$ & $\begin{array}{l}1.33(0.87- \\
2.00)\end{array}$ & 0.185 \\
\hline & Rich & 160 & 99 & $\begin{array}{l}2.22(1.51- \\
3.27)\end{array}$ & $\begin{array}{l}1.76(1.07- \\
2.95)\end{array}$ & .0 .024 \\
\hline \multirow[t]{5}{*}{$\begin{array}{l}\text { Educational } \\
\text { level }\end{array}$} & $\begin{array}{l}\text { Unable to read \& } \\
\text { write }\end{array}$ & 120 & 28 & 1 & 1 & \\
\hline & Able to read \& write & 19 & 17 & $\begin{array}{l}3.83(1.77- \\
8.30)\end{array}$ & $\begin{array}{l}3.60(1.59- \\
7.89)\end{array}$ & 0.002 \\
\hline & Primary education & 166 & 65 & $\begin{array}{l}1.67(1.01- \\
2.77)\end{array}$ & $\begin{array}{l}1.30(0.77- \\
2.20)\end{array}$ & 0.318 \\
\hline & $\begin{array}{l}\text { Secondary } \\
\text { education }\end{array}$ & 130 & 70 & $\begin{array}{l}2.30(1.39- \\
3.81)\end{array}$ & $\begin{array}{l}1.44(0.81- \\
2.57)\end{array}$ & 0.206 \\
\hline & Diploma \& Above & 113 & 56 & $\begin{array}{l}2.12(1.26- \\
3.58)\end{array}$ & $\begin{array}{l}1.04(0.55- \\
1.97)\end{array}$ & 0.900 \\
\hline
\end{tabular}

\section{Discussion}


The prevalence of intention to use IUD in this study was 30\%. This finding was higher than the study conducted in Debre Markos Town, North West Ethiopia(28.3\%), and Adigrat in the Tigray region, North Ethiopia $24.0 \%(9,15)$, and lower than the study from Nekemte town, Ethiopia (47.9\%) (10). The possible explanation for low intention to use IUD might be fear of side effects, rumors, and study setting in which those studies were conducted in an urban setting while our study was conducted in a rural and urban setting.

The common reason for not using IUD was husband disapproval in $14.2 \%$ of the participants, and lack of knowledge in $13.9 \%$. A study in Nepal shows $31.6 \%$ and $23.5 \%$ of the participants cited lack of sufficient knowledge, and husband's disapproval respectively (16). This might be due to the existence of health extension workers in the community in improving the knowledge of women and their partners in Ethiopia.

Intention to use IUD were less likely in the poorest wealth index women compared to women in the average and richest wealth index. Women who have IUD information and able to read and write were more likely to have an intention to use IUD. This study is in line with a study conducted in Uganda, Wolaita Zone, and Mojo, Ethiopia (17-19). The possible reason might be, those exposed to IUD information are more likely to have better knowledge. Although the study includes three different regions of Southwestern Ethiopia where IUD utilization was found to be low, the finding might be affected by social desirability bias.

\section{Conclusion}

Nearly one-third of women have an intention to use IUD, and common reasons cited for not want to use IUD were fear of side effects, lack of knowledge, and husband disapproval. Public health interventions should provide an information focusing on the cited resaons reaching all the community in need, and give priority for women who unable read and write, and lowest wealth status. Further interventional studies were recommended to determine effective interventions to increase women's intention to use intrauterine device.

\section{Abbrevations}

AOR: Adjusted odds ratio; COR: crude odds ratio; Cl: Confidence interval; IUD: intrauterine devices; MSIE: Marie stops international Ethiopia.

\section{Declarations}

\section{Ethics approval and consent to participate}

Ethical clearance was obtained from the Institutional Review Board of Jimma University, Institute of Health school of Post-Graduate Studies. Official letter of cooperation from the University, Gambela regional health bureau, Bench Sheko Zonal health department and Illubabaor Zonal health department were used to communicate respective administrative bodies in the study area. After getting letter of 
permission to carry out the study from each administrative body, informed verbal consent was taken from each study subject prior to interview after the purpose of the study is explained.

\section{Consent for publication}

N/A.

\section{Availability of data and materials}

The data sets used and/or analysed during the current study are available from the corresponding author on reasonable request.

\section{Competing interests}

The authors declare that they have no competing interests.

\section{Funding}

The study was funded by Marie-Stopes international Ethiopia (MSIE)

\section{Authors' contributions}

DA made substantial contributions to conception and design, or data management and quality, or analysis and interpretation of data. TW participated in the design of the study. AK involved analysis and interpretation of data. ZA participated in its coordination, analysis, interpretation of data, and in preparation of the manuscript. AT contribute to the conception and design, analysis and interpretation of data, and revising the manuscript critically for important intellectual content. All authors read and approved the final manuscript.

\section{Acknowledgements}

N/A

\section{References}

1. Street C. Long-term contraceptive protection, discontinuation and switching behaviour.

2. Global FP. 2018 EDITION What 's New in This Edition ? 2018.

3. UNFPA. Universal Access to Reproductive Health. 2016. 20-22 p.

4. Bryant AG, Hamela G, Gottert A, Stuart GS, Kamanga G. Reasons for Intrauterine Device Use, Discontinuation and Non-Use in Malawi : A Qualitative Study of Women and their Partners. African J Reprod Heal December 2015; 19. 2015;19(December):50-7.

5. EDHS. Ethiopia. 2016. 
6. Ethiopian Public Health Institute (EPHI). Ethiopia Mini Demographic and Health Survey 2019: Key Indicators. Rockville, Maryland UE and I, editor. [Ethiopia] and ICF; 2019.

7. Ujah OI, Ocheke AN, Mutihir JT, Okopi JA, Ujah IAO. Postpartum contraception: determinants of intention and methods of use among an obstetric cohort in a tertiary hospital in Jos, North Central Nigeria. Int J Reprod Contraception, Obstet Gynecol. 2017;6(12):5213.

8. Bulto GA, Zewdie TA, Beyen TK. Demand for long acting and permanent contraceptive methods and associated factors among married women of reproductive age group in Debre Markos Town, North West Ethiopia. BMC Womens Health. 2014;14(1).

9. Hinkosa L. Intention to Shift from Short-Acting to Long-Acting Methods of Contraceptives and Its Associated Factors at Axum St.Mary Hospital: A Cross-Sectional Study. Int J Nurs Midwifery Res. 2018;04(04):34-41.

10. Alemu Sufa TT. Factors Affecting Intention to Use Long Acting and Permanent Contraceptive Methods among Married Women of Reproductive Age Groups in Western Ethiopia: A Community Based Cross Sectional Study. Fam Med Med Sci Res. 2015;04(01):1-5.

11. Tilahun Y, Mehta S, Zerihun H, Lew C, Brooks MI, Nigatu T, et al. Expanding access to the intrauterine device in public health facilities in Ethiopia: A mixed-methods study. Glob Heal Sci Pract. 2016;4(1):16-28.

12. Dereje N, Engida B, Holland RP. Factors associated with intrauterine contraceptive device use among women of reproductive age group in Addis Ababa, Ethiopia: A case control study. PLoS One [Internet]. 2020;15(2):1-12. Available from: http://dx.doi.org/10.1371/journal.pone.0229071

13. Animen S, Lake S, Mekuriaw E. Utilization of intra uterine contraceptive device and associated factors among reproductive age group of family planning users in Han Health Center, Bahir Dar, North West Amhara, Ethiopia, 2018. BMC Res Notes. 2018;11(1):1-6.

14. Upadhyay UD, Dworkin SL, Weitz TA, Foster DG. Development and validation of a reproductive autonomy scale. Stud Fam Plann. 2014;45(1):19-41.

15. Alemu Abajobir A. Intention to use Long-acting and Permanent Family Planning Methods among Married 15-49 years Women in Debremarkos Town, Northwest Ethiopia. Fam Med Med Sci Res. 2014;03(04).

16. Jemal Mohammed S, Gebretsadik Kelbore W, Endashaw Yesera G, Shegaze Shimbre M, Assfa Mossa K, Nuriye Metebo K, et al. Determinants of Postpartum IUD Utilization Among Mothers Who Gave Birth in Gamo Zone Public Health Facilities, Southern Ethiopia : a Case-Control Study. Open Access J Contracept. 2020;11.

17. Twesigye R, Buyungo P, Kaula H, Buwembo D. Ugandan women's view of the IUD: Generally favorable but many have misperceptions about health risks. Glob Heal Sci Pract. 2016;4:S73-82.

18. Meskele M, Mekonnen W. Factors affecting women's intention to use long acting and permanent contraceptive methods in Wolaita Zone, Southern Ethiopia: A cross-sectional study. BMC Womens Health. 2014;14(1):1-9. 
19. Gizaw A, Regassa N. Family planning service utilization in Mojo town, Ethiopia: A population based study. J Geogr Reg Plan [Internet]. 2011;4(6):355-63. Available from: http://www.academicjournals.org/JGRP

\section{Figures}

\section{Image not available with this version}

\section{Figure 1}

This image is not available with this version. 